\title{
Non-Hodgkin's lymphoma and nitrate in drinking water: a study in Yorkshire, United Kingdom
}

\author{
Graham Law, Roger Parslow, Patricia McKinney, Ray Cartwright
}

Non-Hodgkin's lymphoma (NHL) is a haematological malignancy with a continuing rise in incidence in the United Kingdom. ${ }^{1}$ The unknown cause may be attributable to changes in environmental risk factors. Various explanations have been proposed including a dysfunctioning immune system, occupational exposure to pesticides or rural residence, ${ }^{2}$ but so far no clear causal factors are forthcoming.

Ingested nitrate produces $\mathrm{N}$-nitroso compounds, after amination in the stomach, with known carcinogenic properties. Two recent American studies have shown a positive association between drinking water nitrate and $\mathrm{NHL}^{34}$ and this study has investigated the association for the first time in the United Kingdom.

\section{Methods}

A population-based incidence register of NHL has been collected by the Leukaemia Research Fund since 1 January 1984, completing 160 million person years of surveillance for approximately $25 \%$ of the UK population. ${ }^{5}$ This study included cases in 0-79 year olds, diagnosed during 1984-93, resident within the supply areas of Yorkshire Water plc or the York Water Company who distribute drinking water to West, South and North Yorkshire and North Humberside (population 3.06 million persons). All Kiel types were pooled and subdivided into nodal (lymph nodes, marrow, blood, tonsils) and extra-nodal disease.

Domestic water in England is regulated under the Water Industry Act 1991, and distribution networks must be divided into geographically distinct Water Supply Zones (WSZs) with less than 50000 residents. Water supplied within a WSZ has the same chemical composition at any one time. A total of 9330 tap water measurements were available from 148 WSZs, covering six years (1990-95) (table 1). Nitrate was measured according to guide-

Table 1 Demographic characteristics of the Water Supply Zones (WSZ) in the study

\begin{tabular}{llll}
\hline WSZ $(n=148)$ & Mean & Minimum & Maximum \\
\hline Area (hectares) & 6780 & 91 & 61252 \\
Population & 20702 & 61 & 51148 \\
Population density† & 12.47 & 0.04 & 54.19 \\
Nitrate concentration $(\mathrm{mg} / \mathrm{l}) \ddagger$ & 11.86 & 1.48 & 40.01
\end{tabular}

${ }^{\star} 0-79$ years of age. $\nmid$ Persons per hectare. $\ddagger$ Mean of the monthly mean. lines regulated by the Drinking Water Inspectorate, at a single laboratory where random samples from consumers taps are subject to mandatory quality control. Annually, nitrate levels oscillate around an average, because of seasonal factors, and therefore exposure was calculated as the mean of the monthly mean.

Age-sex specific population counts from the 1991 census (ESRC purchase, Crown Copyright) were linked to a WSZ using a Geographical Information System, as described elsewhere, ${ }^{6}$ forming the underlying susceptible population. Poisson regression models were fitted to observed counts of cases within each WSZ using the log of the number of expected cases, derived from age-sex standardised incidence rates, as the offset. Population density (persons per hectare) and nitrate were assigned into three categories with approximately equal number of persons in each level (table 2). Population density was included as a proxy for urban/rural status, as previous research has shown rural habitation is a risk factor for NHL. ${ }^{7}$ The effect of removing nitrate exposure from the model was tested using the likelihood ratio statistic and the simplest model was chosen based on significant improvement in model fit. The incidence rate ratio is reported as a measure of association and poor model fit caused by extra-Poisson variation was corrected using the method of Breslow. Modelling was repeated for nodal and extra-nodal sites, time period at diagnosis (1984-88, 1989-93) and age group (0-59, 60-79), as evidence suggests these subsets have potentially distinct aetiologies.

\section{Results}

There were no significant associations between NHL incidence and explanatory variables for all cases combined. For 1984-88, nitrate was retained in the model and had a significant positive association with the incidence of NHL at both the second and highest levels above baseline. In contrast, removing nitrate from the model for the second time period, 1989-93, did not significantly reduce model fit. There was no association between nitrate or population density and NHL in the two age groups or in extra-nodal cases. The rate ratio for level 2 of nitrate was significantly raised for nodal sites, however, that of the highest level of nitrate exposure was not significantly raised. Model 
Table 2 Association of nitrate concentrations in drinking water and population density with NHL: incidence rate ratios (IRR) for chosen Poisson regression model (using likelihood ratio test to choose model)

\begin{tabular}{|c|c|c|c|c|c|}
\hline Group & Incidence $^{\star}$ (obs) & Variable & Level & $I R R$ & $95 \%$ CIt \\
\hline \multirow[t]{3}{*}{$\overline{\text { All }}$} & \multirow[t]{3}{*}{$8.61(2637)$} & \multirow[t]{3}{*}{ Population density $\ddagger$} & 1 & 1 & - \\
\hline & & & 2 & 1.104 & $0.92,1.17$ \\
\hline & & & 3 & 0.943 & $0.84,1.06$ \\
\hline \multirow[t]{6}{*}{$1984-88$} & \multirow[t]{6}{*}{$7.76(1188)$} & \multirow[t]{3}{*}{ Population density } & 1 & 1 & - \\
\hline & & & 2 & 1.106 & $0.96,1.27$ \\
\hline & & & 3 & 0.857 & $0.74,0.99$ \\
\hline & & \multirow[t]{3}{*}{ Nitrate $\$$} & 1 & 1 & - \\
\hline & & & 2 & 1.170 & $1.01,1.35$ \\
\hline & & & 3 & 1.210 & $1.04,1.41$ \\
\hline \multirow[t]{6}{*}{ 1988-93 } & \multirow[t]{6}{*}{$9.46(1449)$} & \multirow[t]{3}{*}{ Population density } & 1 & 1 & - \\
\hline & & & 2 & 1.000 & $0.86,1.17$ \\
\hline & & & 3 & 1.028 & $0.88,1.21$ \\
\hline & & \multirow[t]{3}{*}{ Nitrate } & 1 & 1 & - \\
\hline & & & 2 & 1.069 & $0.92,1.25$ \\
\hline & & & 3 & 0.917 & $0.78,1.08$ \\
\hline \multirow[t]{3}{*}{$0-59$} & \multirow[t]{3}{*}{$4.19(1048)$} & \multirow[t]{3}{*}{ Population density } & 1 & 1 & - \\
\hline & & & 2 & 1.138 & $0.98,1.32$ \\
\hline & & & 3 & 0.962 & $0.83,1.12$ \\
\hline \multirow[t]{6}{*}{$60-79$} & \multirow[t]{6}{*}{28.37 (1589) } & \multirow[t]{3}{*}{ Population density } & 1 & 1 & - \\
\hline & & & 2 & 0.987 & $0.85,1.15$ \\
\hline & & & 3 & 0.951 & $0.81,1.11$ \\
\hline & & \multirow[t]{3}{*}{ Nitrate } & 1 & 1 & - \\
\hline & & & 2 & 1.137 & $0.98,1.32$ \\
\hline & & & 3 & 0.975 & $0.83,1.15$ \\
\hline \multirow[t]{6}{*}{ Nodal } & \multirow[t]{6}{*}{$5.10(1561)$} & \multirow[t]{3}{*}{ Population density } & 1 & 1 & - \\
\hline & & & 2 & 1.046 & $0.91,1.20$ \\
\hline & & & 3 & 0.962 & $0.83,1.11$ \\
\hline & & \multirow[t]{3}{*}{ Nitrate } & 1 & 1 & - \\
\hline & & & 2 & 1.254 & $1.09,1.45$ \\
\hline & & & 3 & 1.100 & $0.94,1.28$ \\
\hline \multirow[t]{3}{*}{ Extra-nodal } & \multirow[t]{3}{*}{2.95 (905) } & \multirow[t]{3}{*}{ Population density } & 1 & 1 & - \\
\hline & & & 2 & 1.102 & $0.93,1.30$ \\
\hline & & & 3 & 0.927 & $0.78,1.10$ \\
\hline
\end{tabular}

${ }^{\star}$ Internally standardised incidence rate per 100000 persons per year. †Corrected for extra-Poisson variation; significant at $\mathrm{p}<0.05$ in bold. $¥$ Persons per hectare; $1>18.39,2$ $6.91-18.39,3<6.91$. Mean of the monthly mean of nitrate in $\mathrm{mg} / 1 ; 1<3.24,23.24-14.85,3$ $>14.85$. of dose response or significance of the highest category suggest confounding with a further unmeasured variable. Population density, always included during the modelling process, reduced the likelihood of observing nitrate as a confounder for factors associated with rural habitation.

Nitrate measurements represented a six year time period, during which $81 \%$ of all WSZs did not change. ${ }^{6}$ Historical data before 1990 were not systematically collected, and analyses of these data would not be possible. However, systematic migration of those persons with NHL initiated, but not diagnosed, to a lower water nitrate region, which could account for the lack of consistent association, is unlikely.

Studies using areal units of analysis assign an exposure to all persons based on the properties of the area. However, despite heterogeneity across the study area each geographical unit of analysis (WSZ) was internally homogenous with respect to nitrate levels. The small geographical areas of the WSZs and homogeneity of water quality within a WSZ, lead to an accurate picture of the population structure and nitrate exposure from drinking water. Added to this, a survey reported $99 \%$ of all households in the United Kingdom drink tap water, and $77 \%$ of total liquid consumption is derived from tap water. ${ }^{7}$ Measuring nitrate load using this method avoids reporting bias from people and inherent problems with dietary studies of people, particularly the evaluation of micronutrient ingestion.

Despite the observed association in the first time period between nitrate and incidence of NHL, the trend or significant associations do not persist into the second half of the data collection period and was not evident for the entire period. These results do not provide substantial evidence to support the hypothesis that nitrate in drinking water is an initiator or promoter of non-Hodgkin's lymphoma, in contrast with previous studies.

The authors would like to thank the reviewers for their helpful comments and are grateful to Yorkshire Water plc and the York Water Company for their assistance.

Funding: the register is fully supported by the Leukaemia Research Fund.

Conflicts of interests: none.

1 McNally RJQ, Alexander FE, Staines A, et al. A comparison of 3 methods of analysis for age-period-cohort models with application to incidence data on non-Hodgkin's lymphoma. Int f Epidemiol 1997;26:32-46.

2 Cantor KP, Blair A, Everett G, et al. Pesticides and other agricultural risk factors for non-Hodgkin's lymphoma among men in Iowa and Minnesota. Cancer Res 1992;52: 2447-55.

3 Weisenburger DD. Potential health consequences of Weisenburger DD. Potential health consequences of
ground-water contamination by nitrates in Nebraska. Nround-water contamination

4 Ward MH, Mark SD, Cantor KP, et al. Drinking water nitrate and the risk of non-Hodgkin's lymphoma. Epidemiology 1996;7:465-71.

5 Parslow RC, McKinney PA, Law GR, et al. Incidence of childhood diabetes in Yorkshire, Northern England, is associated with nitrate in drinking water: an ecological analysis. Diabetologia 1997;40:550-6.

6 Blair A, Malker H, Cantor KP, et al. Cancer among farmers. Scand $\mathcal{F}$ Work Environ Health 1985;11:397-407.

7 MEL Research. Tap water consumption in England and Wales: findings from the 1995 national survey. London: HMSO, 1996. 